\title{
Tidal variation in the settling diameters of suspended matter on a tidal mud flat
}

\author{
Karen Edelvang \\ Institute of Geography, University of Copenhagen; \\ Oster Voldgade 10, DK-1350 K Copenhagen, Denmark*
}

\begin{abstract}
During one tidal period, measurements of the variation of current velocities, suspended sediment concentration and settling velocities of the suspended matter were carried out on a tidal mud flat $1.8 \mathrm{~km}$ west of Ballum Sluse in the northern part of the Lister Dyb tidal basin. The settling velocities have been converted to equivalent settling diameters. Current velocities follow a variation pattern well-known from other parts of the Wadden Sea. Variations in current velocities are responsible for the variation in suspended sediment concentration and thereby indirectly control the equivalent particle sizes, because high suspended sediment concentration favours the formation of flocs. Maximum concentrations of up to $532 \mathrm{mg} / \mathrm{l}$ were recorded at the beginning of the flood period and at the end of the ebb period, when current velocities are high. This is reflected in the median equivalent settling diameters, which show corresponding high values of $83 \mu \mathrm{m}$ at the beginning of the flood period and $96 \mu \mathrm{m}$ at the end of the ebb period.
\end{abstract}

\section{INTRODUCTION}

Most investigations in the tidal environment deal with the dynamics in tidal channels. In order to describe the tidal variation in the concentration of suspended sediment and the settling velocities of suspended matter on a tidal flat, a tower was erected on the tidal mud flat west of the mouth of a small Danish river, Brede $\AA$. This site was selected because it is located in the high turbidity zone of the northern termination of the Lister Dyb tidal basin.

The settling velocities of suspended matter are known to be increased by flocculation. The formation of flocs is mainly dependent on the concentration of suspended sediment (Kranck, 1975; Krone, 1978; Burt, 1986; Pejrup, 1988a), and on differential settling and turbulence (McCave, 1984). Tidal variations in current velocities across a tidal flat are responsible for the variation in suspended sediment concentration, influencing the rate of flocculation and the size of the flocs (McCave, 1984; Pejrup, 1988b; Edelvang, 1995).

This investigation was carried out in order to describe the variation in in-situ settling diameters found on a tidal mud flat, being one of the sites where the fine-grained sediment found in suspension in this specific tidal environment is deposited. The objectives are to add to the common knowledge of in-situ processes concerning the formation of flocs and to link the temporal tidal variation to this process.

\footnotetext{
- Present address: Danish Hydraulic Institute; Agern Allé 5, DK-2970 Hoersholm, Denmark 


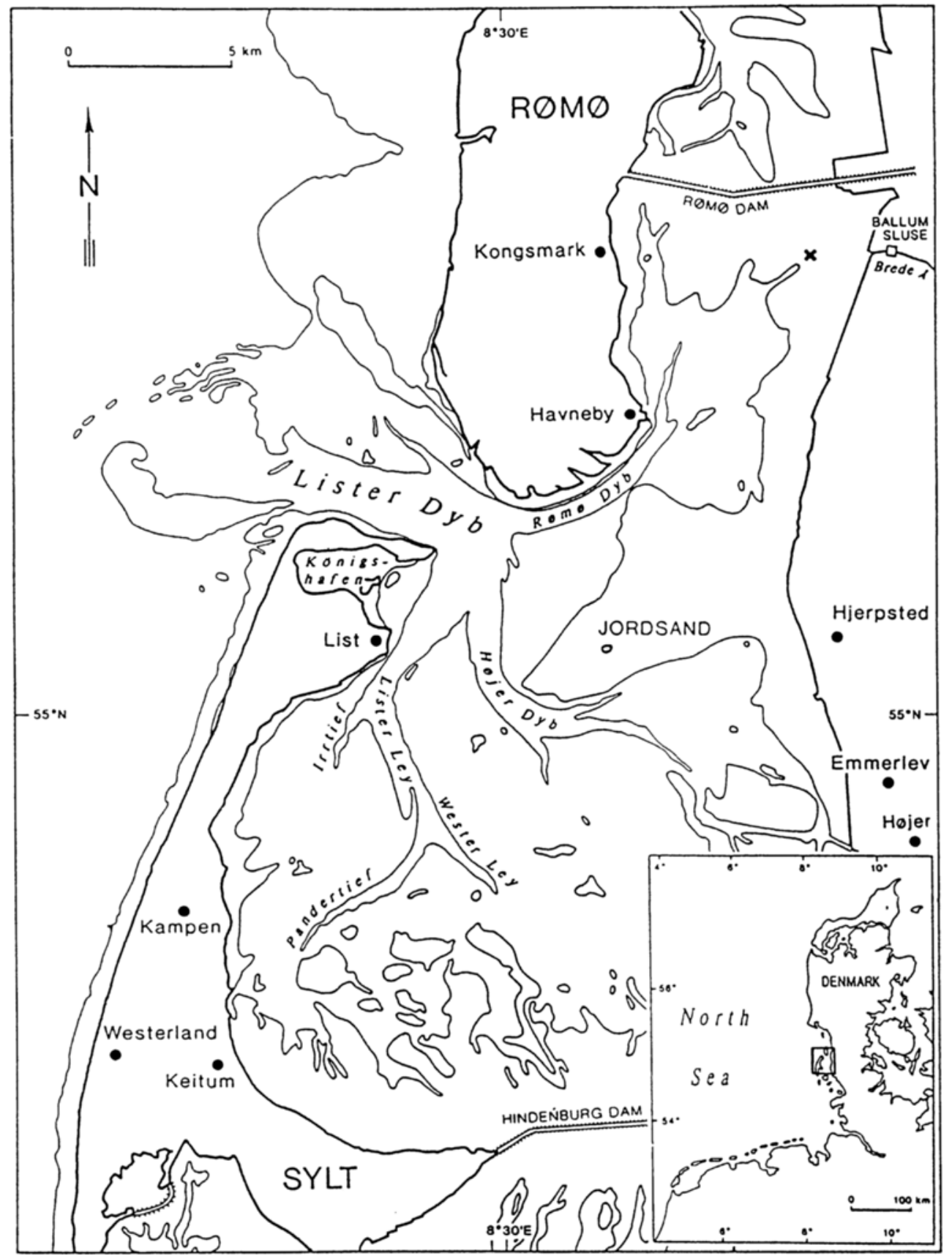

Fig. 1. Lister Dyb tidal basin. The measuring tower is indicated by a cross (x). Depth contours of mean low tide and $-5 \mathrm{~m}$ are shown 


\section{STUDY AREA}

The Lister Dyb tidal area is located in the northern part of the Wadden Sea behind the barrier islands Rømø and Sylt. It is bound on the south by the German Hindenburg Dam and on the north by the Danish Rømø Dam.

In the northeastern corner of the Lister Dyb area, at the mouth of the river Brede $\AA$, a tower was erected on the tidal mud flat $1.8 \mathrm{~km}$ west of Ballum Sluse on the mainland (Fig. 1). During normal weather conditions, the maximum water depth at the tower is $1.5 \mathrm{~m}$, the flood period is shortened to $5 \mathrm{~h}$, the ebb period prolonged to $7 \frac{1}{2} \mathrm{~h}$ as a result of the deformation of the shoaling tidal wave as it moves northward through the tidal lagoon.

On 24th May 1993 the weather was calm, changing from overcast in the morning to bright sunshine in the course of the day. Air temperature varied between $15^{\circ}-18^{\circ} \mathrm{C}$. The tidal flat was covered with water for $6 \frac{1}{4} \mathrm{~h}$ during the investigated tidal period.

\section{METHODS}

On 24th May 1993, current velocities, settling velocities and suspended sediment concentrations were measured over one tidal cycle.

Current velocities as well as temperature and salinity were measured continuously using an Aanderaa RCM7 current meter positioned $0.3 \mathrm{~m}$ above the sea bottom. Furthermore, velocity profiles were measured every half-hour with an Ott C31 current meter with 5 points in each profile: at $0.1,0.2,0.3 \mathrm{~m}$ above the bottomi at middepth, and at the surface when depths exceeded $0.4 \mathrm{~m}$. Mean current velocities were computed from the total number of points in the profile. The 3 bottom points were interpolated logarithmically, the top points linearly. Mean current velocity was determined as the depth integral of the measured velocity profile. The velocities computed by this method showed good consistency with the velocity $0.3 \mathrm{~m}$ above the bottom measured continuously with the Aanderaa current meter with a $\mathrm{r}^{2}$ of 0.57 .

In order to describe the relation between current velocities and suspended sediment concentration, the velocities measured continuously $0.3 \mathrm{~m}$ above the bottom were squared as "The resulting turbulent shear stress has been experimentally observed to be proportional to the square of the time averaged velocity, " $\left(\tau \sim V^{2}\right)(D y e r, 1986)$. Sternberg (1971), basing his arguments on investigations in Puget Sound, Washington, stated in the same way that the mean bottom velocity measured $1 \mathrm{~m}$ above the bottom agreed with experimentally derived competency curves, and therefore used this velocity in his estimates of $\tau_{0}$.

Water samples were automatically collected every 15 minutes at $0.3 \mathrm{~m}$ above the bottom with an ISCO 2700 water sampler to determine the variation of suspended sediment concentration. In-situ settling velocities of the suspended matter were measured at 45min intervals $0.3 \mathrm{~m}$ above the bottom and $0.2 \mathrm{~m}$ below the surface alternatingly, using Braystoke SK 110 settling tubes.

Subsamples from the settling tube analyses were filtered through Millipore CEM filters with a nominal retention of $0.45 \mu \mathrm{m}$. Equivalent settling diameters of the samples were computed using Stoke's law from the measured settling velocities. ISCO samples were filtered through $0.7 \mu \mathrm{m}$ Whatmann GF/F filters. The sediment mass was determined to $\pm 0.1 \mathrm{mg}$. 


\section{RESULTS}

Flooding of the tidal flat

The temporal variation in water depth, mean depth-averaged current velocity, and current velocity at $0.3 \mathrm{~m}$ above the bottom are shown in Figure 2. On 24th May 1993 the flood period set in at about 14:00 with the arrival of a $0.1 \mathrm{~m}$ high wave inundating the tidal flat. This phenomenon has been observed at the beginning of several tidal periods. It is caused by the deformation of the tidal wave. The tidal wave reaching the shallow tidal flat area at the northern limit of the Lister Dyb area takes the form of a prograding tidal wave which rapidly inundates the flats.

Fifteen minutes later the water depth was $0.3 \mathrm{~m}$, increasing steadily during the rest of the flood period to reach a maximum depth of $1.2 \mathrm{~m}$ at high water slack at 17:15. During the ebb period the water depth decreased steadily, following the variation in the accelerating current velocity draining the tidal flats.

\section{Mean depth-averaged current velocity}

The temporal variation of the mean depth-averaged current velocity (Fig. 2) follows the same general trend observed at $0.3 \mathrm{~m}$ above the bottom, although the velocities are somewhat higher. Maximum values are found near the end of the ebb period.

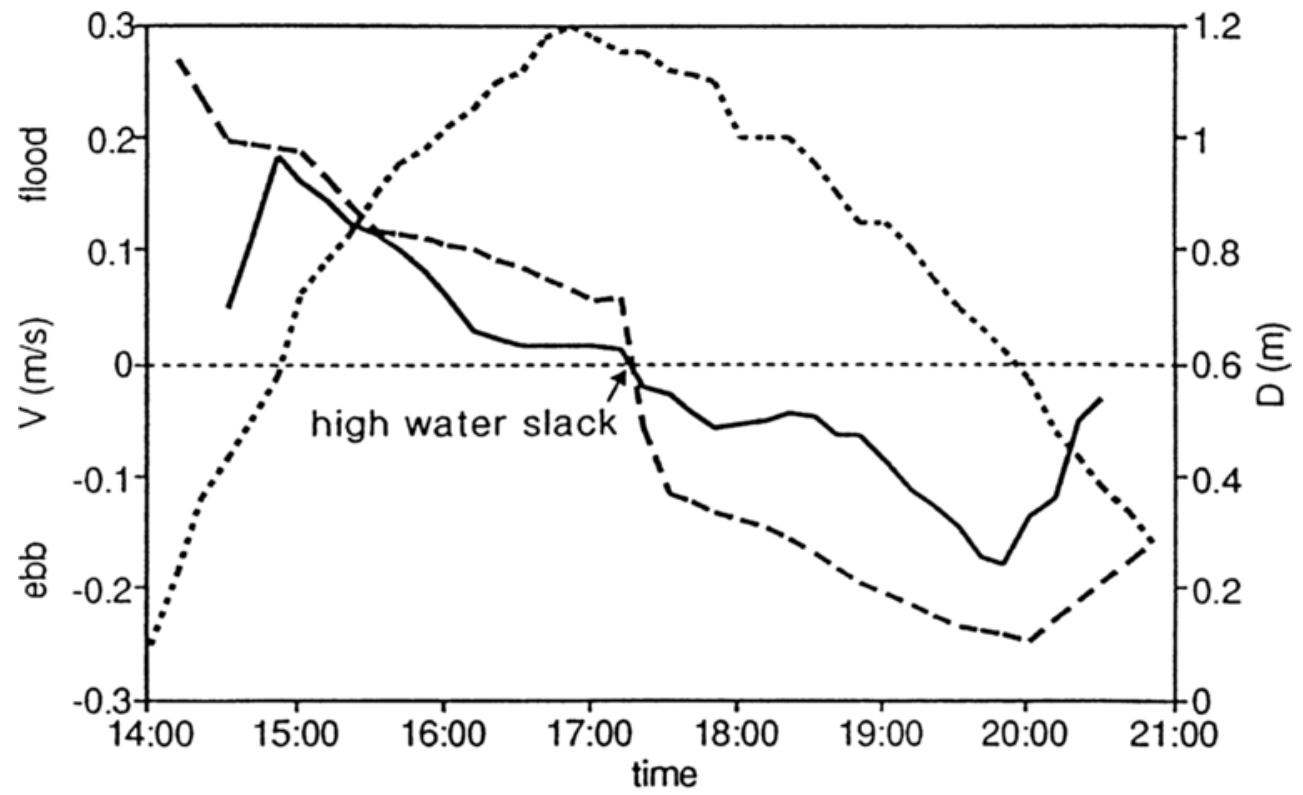

-.... water depth velocity $0.3 \mathrm{mab}-\cdots \cdot$ mean velocity

Fig. 2. The variation of depth (D), mean depth-averaged, current velocity (V), and current velocity $0.3 \mathrm{~m}$ above the bottom over one tidal cycle (24th May 1993) 
At the beginning of the flood period, at 14:00, a current velocity of $0.27 \mathrm{~m} / \mathrm{s}$ was measured on the flat at $0.1 \mathrm{~m}$ above the bottom at a water depth of $0.18 \mathrm{~m}$. This is the situation at the very beginning of the flood period at the study site, when the tidal flat is being rapidly flooded by the prograding tidal wave. Mean depth-averaged current velocities decrease steadily from a maximum at the very beginning of the flood period to zero at high water slack.

In the ebb period, mean depth-averaged current velocities increase steadily and reach maximum values at about 20:00, shortly before the end of the period, with velocities of up to $0.22 \mathrm{~m} / \mathrm{s}$ caused by the fast draining of the tidal flat. The above current pattern is well known from other parts of the Danish Wadden Sea (Pejrup, 1988b; Edelvang \& Larsen, 1995).

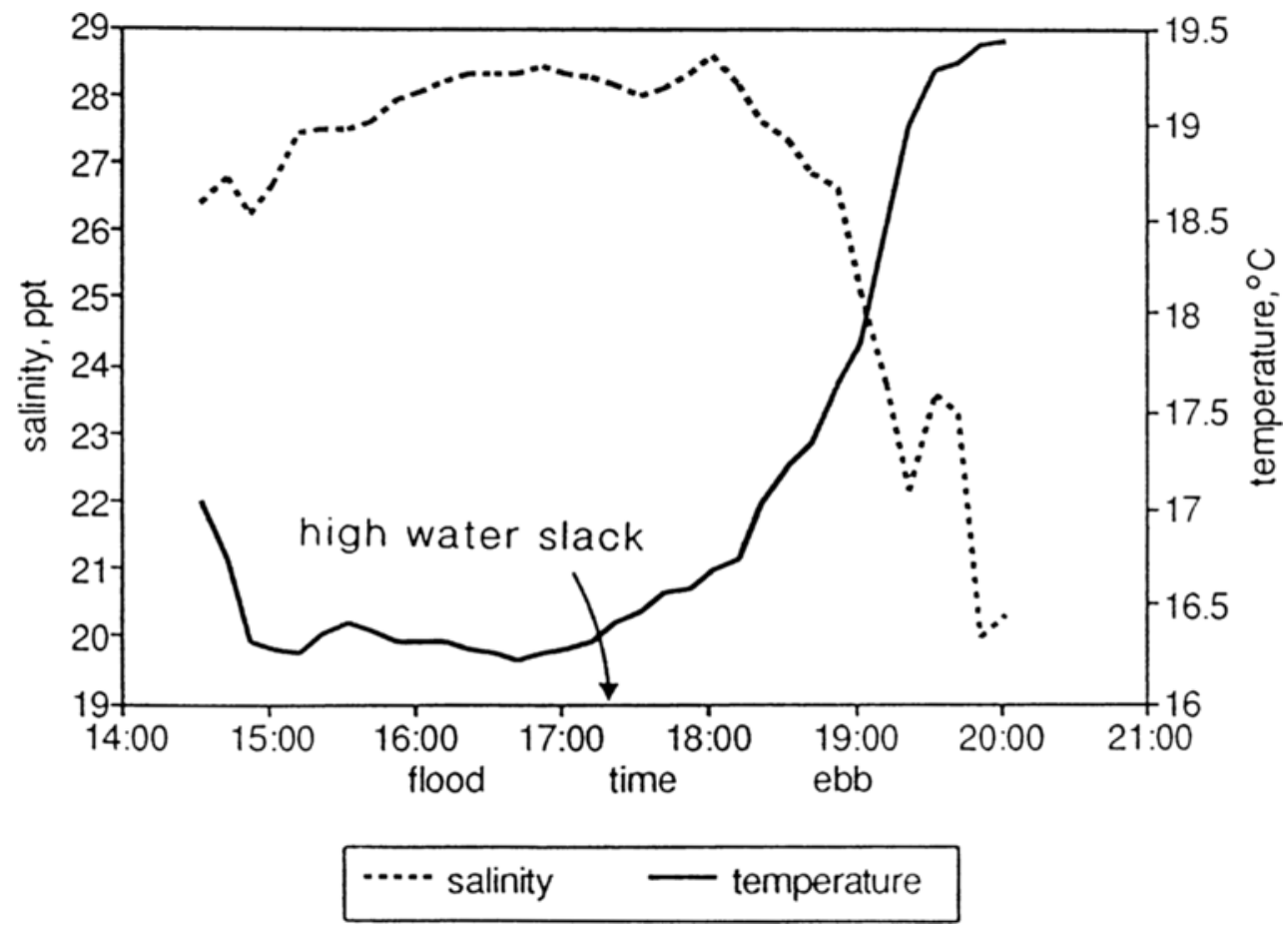

Fig. 3. Salinity and temperature variation over one tidal cycle

\section{Salinity and temperature}

The temporal variation of salinity and temperature is illustrated in Figure 3 . Salinity increased at the beginning of the flood period from 26.5 to 28.5 within the first hours as a result of the entering tidal wave. Salinity then remained constant throughout the remainder of the flood period and the beginning of the ebb period until it again decreased when being mixed with more brackish water from the inner parts of the tidal lagoon. A minimum salinity of $20 \%$ was reached shortly before the tidal flat became totally drained at the end of the ebb period. 
Water temperature decreased rapidly at the very beginning of the flood period from $18^{\circ} \mathrm{C}$ to $16.3^{\circ} \mathrm{C}$ under the influence of the mixing with cold North Sea water entering the area. The mean water temperature during the rest of the flood period remained constant. It then increased at the beginning of the ebb period to reach a maximum value of $19.5^{\circ} \mathrm{C}$ shortly before the tidal flat fell dry.

The rapid increase in water temperature during the ebb period is caused by the water coming from the inner parts of the estuary. Close to the mainland, the level of the tidal flats is higher, leaving them dry for a longer period of time during the flood period. This means that they have been heated up by the afternoon sun. Once the flats are flooded, the warm surface of the tidal flat transfers heat to the water during the few hours of inundation.

\section{Suspended sediment concentration}

Suspended sediment concentration at $0.3 \mathrm{~m}$ above the bottom reached a maximum value of $203 \mathrm{mg} / \mathrm{l}$ at the beginning of the flood period, coinciding with maximum current velocity. Comparing the temporal variation in concentration at $0.3 \mathrm{~m}$ above the bottom with $\mathrm{V}^{2}(0.3)$ (Fig. 4), it can be seen that suspended sediment concentration is positively correlated with the squared velocity, thus explaining the temporal trend in concentration.

The concentration decreased following the deceleration in current velocity and remained low through high water slack into the early stages of the ebb period. This demonstrates that the temporal variation of suspended sediment concentration is governed
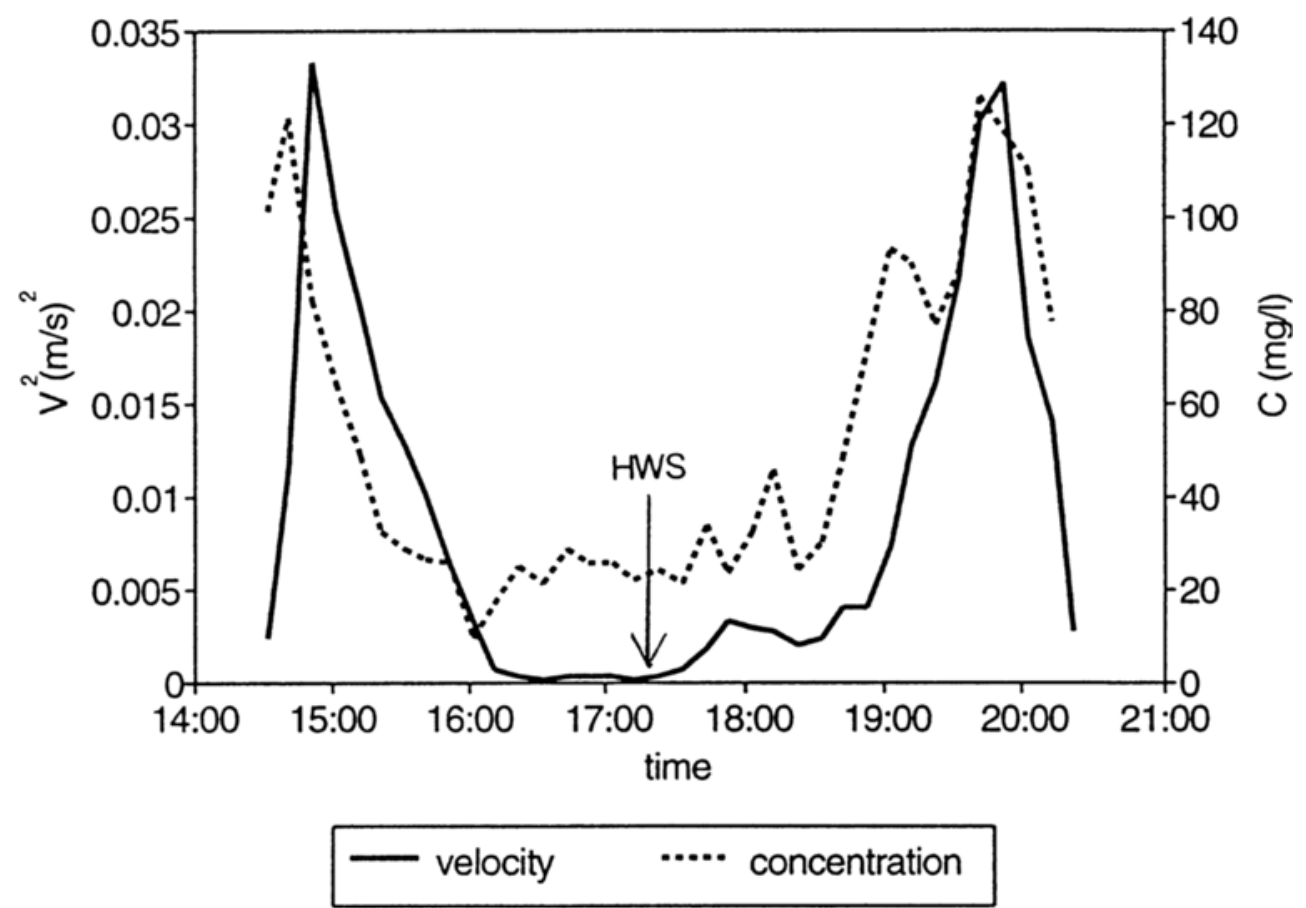

Fig. 4. Suspended sediment concentration $0.3 \mathrm{~m}$ above the bottom measured with the ISCO, compared to the square of the current velocity at the same level. HWS = high water slack 


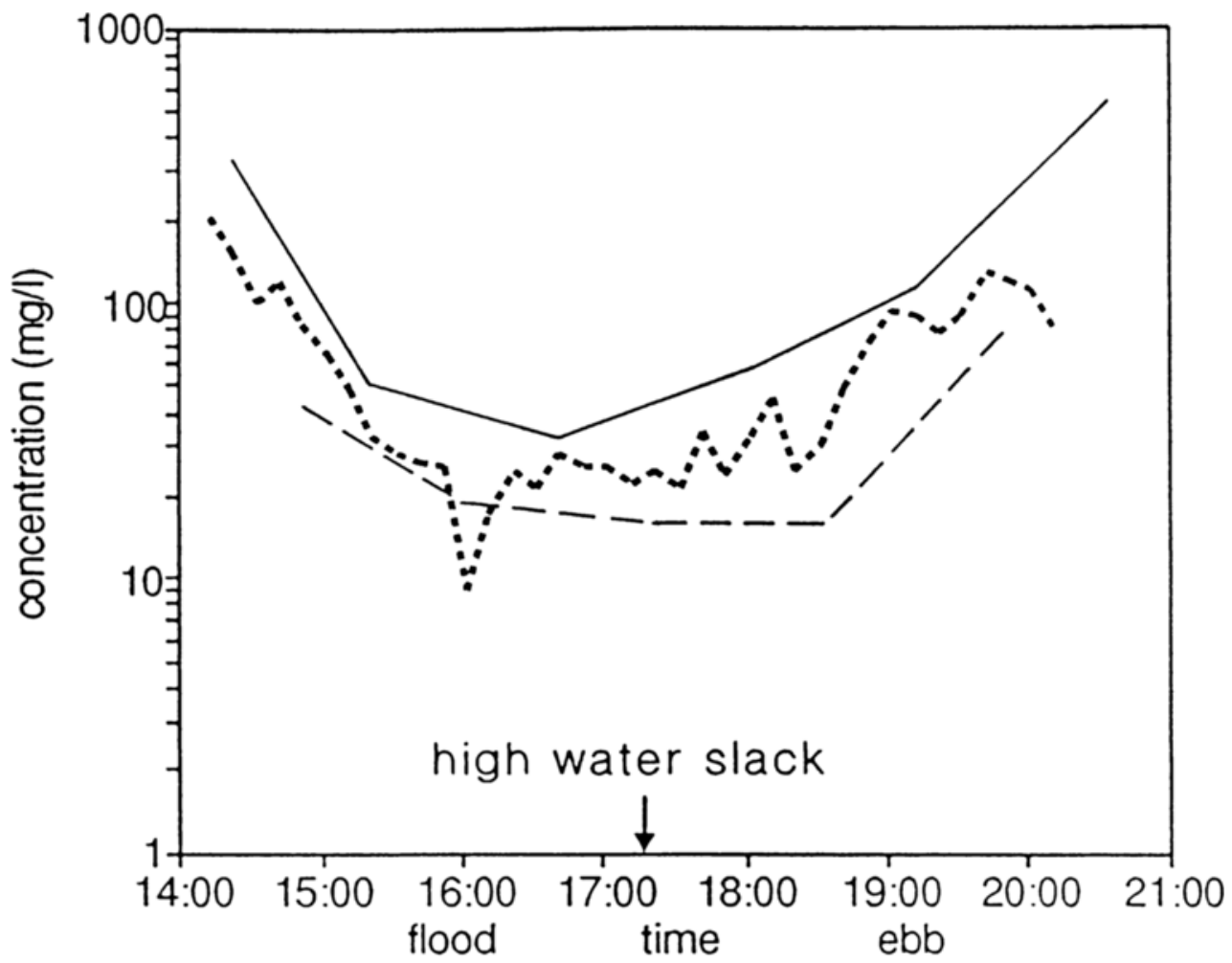

$$
\cdots \text { C (ISCO) - C (tube) bottom - -C (tube) surface }
$$

Fig. 5. Suspended sediment concentration in the settling tubes

by local bottom erosion and not by an advective supply of sediment. As velocities accelerate in the ebb period draining the tidal flat, resuspension of the sediment that settled around high water slack takes place. Concentrations increase following the current velocity until all erodible sediment is brought into suspension. The remaining cohesive sediment on the tidal mud flat forms a coherent layer that does not further erode at the applied shear stress.

Suspended sediment concentrations in the settling tubes

It is shown that in the settling tubes (Fig. 5) concentrations are highest at the bottom with an absolute maximum of $532 \mathrm{mg} / \mathrm{l}$ at the end of the ebb period. Surface concentrations vary between 16 and $84 \mathrm{mg} / \mathrm{l}$. At low current velocities, concentrations at the surface as well as at the bottom are low. Around high-water slack minimum values in concentration of $16 \mathrm{mg} / \mathrm{l}$ at the surface and $33 \mathrm{mg} / \mathrm{l}$ at the bottom were recorded. The temporal trend in suspended sediment concentration in the settling tubes follows that of the 
ISCO samples except at maximum current velocity, where the settling tube samples from the bottom show higher concentrations.

This was true for the bottom samples taken at 14:23, shortly after flooding of the tidal flat had set in, and at 20:30, at maximum current velocity. The difference between the two sampling methods is probably due to the fact that the settling tube samples are momentary, whereas the ISCO samples were integrated over a period of about one minute, depending on the suction head. Furthermore, bursting caused by vortices may have an influence on the high concentration momentary samples, as bursting mostly occurs in situations of high turbulence (Dyer, 1986).
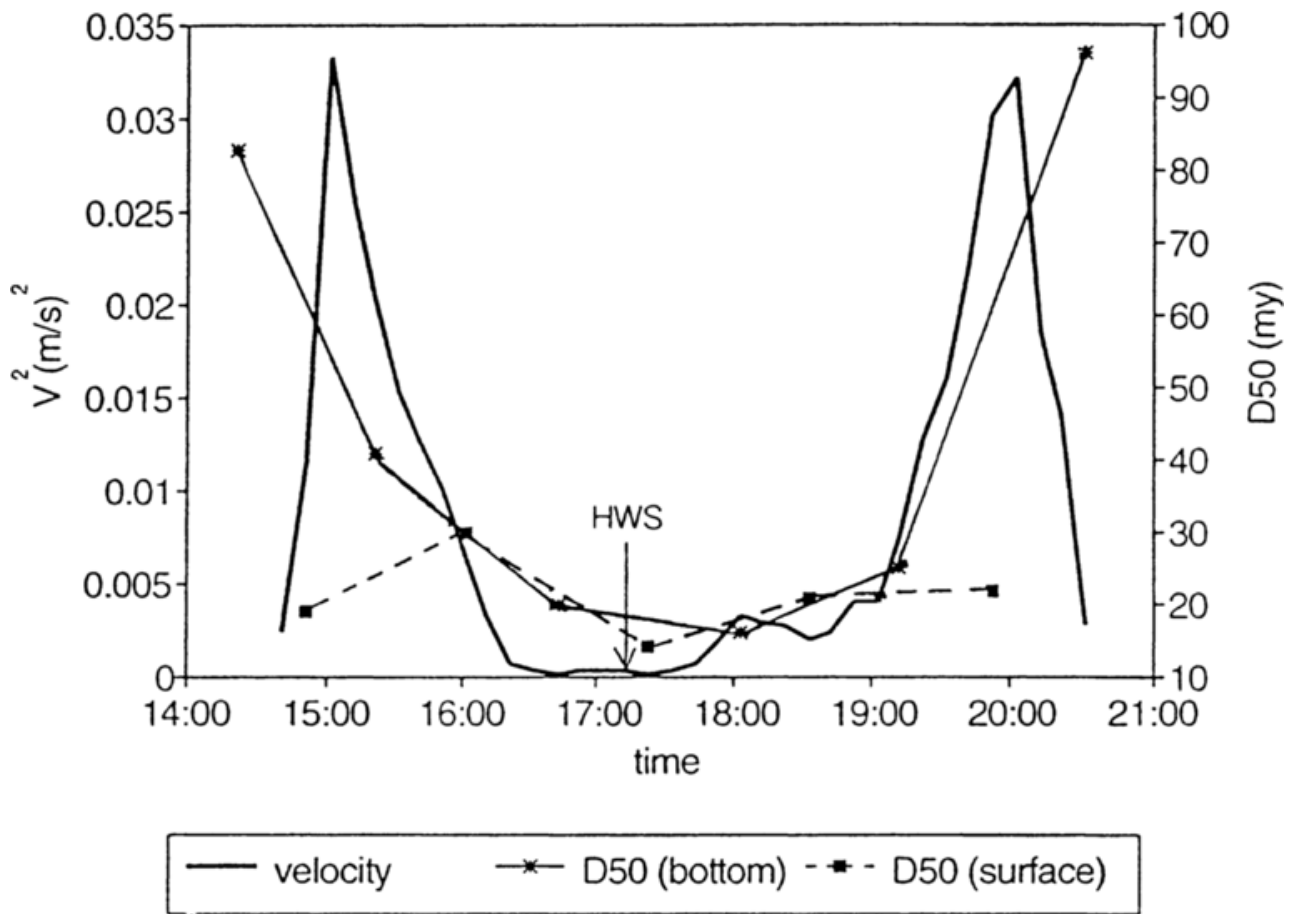

Fig. 6. Median equivalent settling diameters (D50) measured with the settling tubes

Equivalent median settling diameters of the sediment

Median settling diameters of the sediment at the surface were very constant at about $20 \mu \mathrm{m}$, following the temporal variation in concentration (Fig. 6). At the bottom, the settling diameters are also dependent on concentration following the temporal variation in current velocities. Maximum median settling diameters of 83 and $96 \mu \mathrm{m}$ are seen at the beginning of the flood and the end of the ebb period, respectively. At low concentrations, median settling diameters at the surface and the bottom are the same.

At the beginning of the flood period, the large median settling diameter at the bottom is related to resuspension of sediment deposited during the previous low-water slack 
giving high suspended sediment concentrations. The rapidly accelerating current at the beginning of the flood phase favours high shear stresses, thus enabling large quantities of sediment to be resuspended. Large single grains are also resuspended, although a large proportion of the resuspended material is thought to consist of fecal pellets from the numerous Hydrobia ulvae feeding on the tidal flat (Lackschewitz, 1995). This is consistent with results from another investigation in the area (Edelvang \& Austen, 1997), showing that high concentrations of fecal pellets from $H$. ulvae are present around lowwater slack.

An earlier investigation by Bale et al. (1989) concludes that particle diameters are at a maximum during slack water, when concentrations are high and current velocities low. However, Bale's investigation deals with the physical size of the flocs compared to the equivalent floc diameters in the present study, where it is indicated that large, low-density flocs have settling velocities much slower than smaller, more compact flocs formed during turbulent conditions or forming part of fecal pellets. The suggestion in this paper is supported by the fact that Fennessy et al. (1994), using the INSSEV, observed many large, low-density flocs.

Investigating the estuaries of the rivers Elbe and Dollard using an in-situ camera, Eisma et al. (1994) also found the largest flocs generally around slack. Again the in-situ camera projects the physical size of the flocs, but does not include the density of the suspended matter. However, the investigations agree regarding the relationship between the maximum floc size and the suspended matter concentration as is also shown in the present investigation.

The grain size diagram in Figure 7a shows that at the surface the distribution of the different size fractions is very similar in all the settling tube analyses, whereas there is greater variability in the bottom samples (Figure $7 \mathrm{~b}$ ). At the surface no sediment is seen to have equivalent settling diameters coarser than $130 \mu \mathrm{m}(2.95 \Phi)$, whereas at the bottom up to $20 \%$ are coarser than this upper limit. This is particularly evident in the samples taken at $14: 23$ and $20: 30$ at $0.3 \mathrm{~m}$ above the bottom, which have equivalent median settling diameters of 83 and $96 \mu \mathrm{m}$, respectively. They were both collected at high concentration and high current velocity.

\section{DISCUSSION AND CONCLUSIONS}

The results of the measurements carried out on 24th May 1993 show that the temporal variation in salinity and temperature is accounted for by tidal variation. Both temperature and salinity are dependent on whether the water passing the station originates from the North Sea or from the inner parts of the tidal lagoon.

Current velocities follow a pattern well known from other parts of the Danish Wadden Sea. The asymmetry of the tidal current velocities is explained by the location of the measuring station at the northernmost limit of the Lister Dyb tidal basin. Current velocities rapidly increase at the beginning of the flood period when the tidal wave reaches the shallow areas. In the ebb phase, maximum velocities are delayed until the end of the period when the tidal flats are being drained. During normal weather conditions, the tidal flats fall completely dry over part of the tidal period.

The temporal trend in suspended sediment concentration is well described by the variation in bottom shear stress expressed as $\mathrm{V}^{2}{ }_{(0.3)}$. Maximum concentrations are recorded 


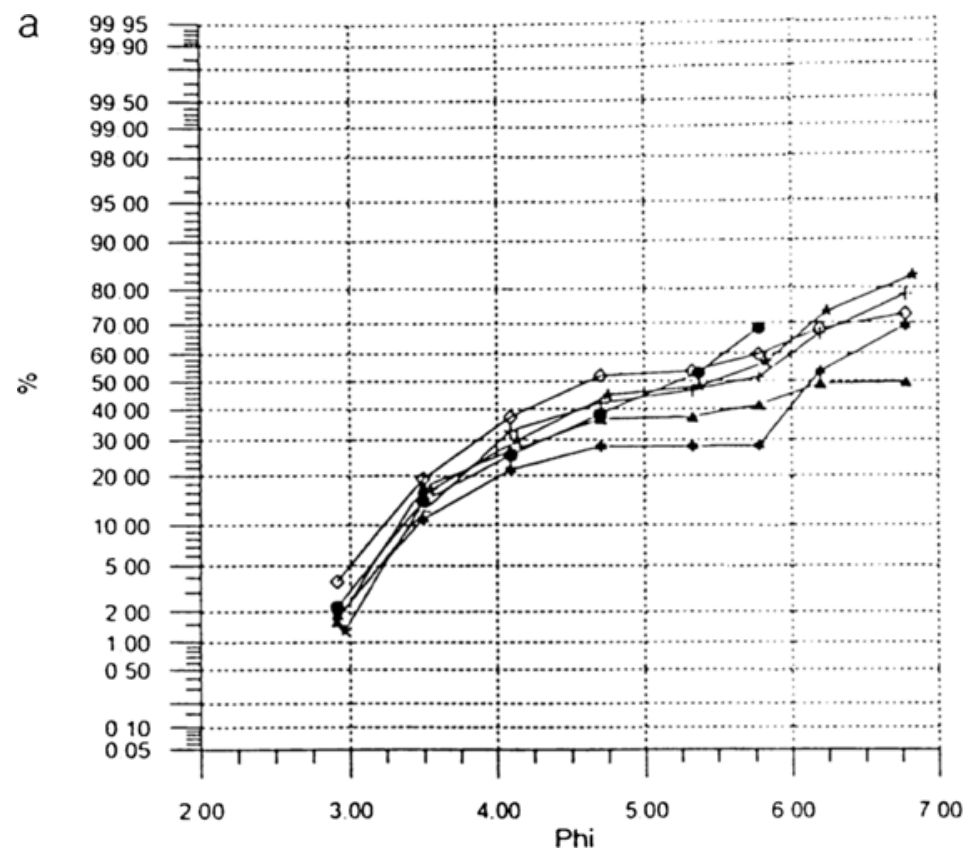

surfacc
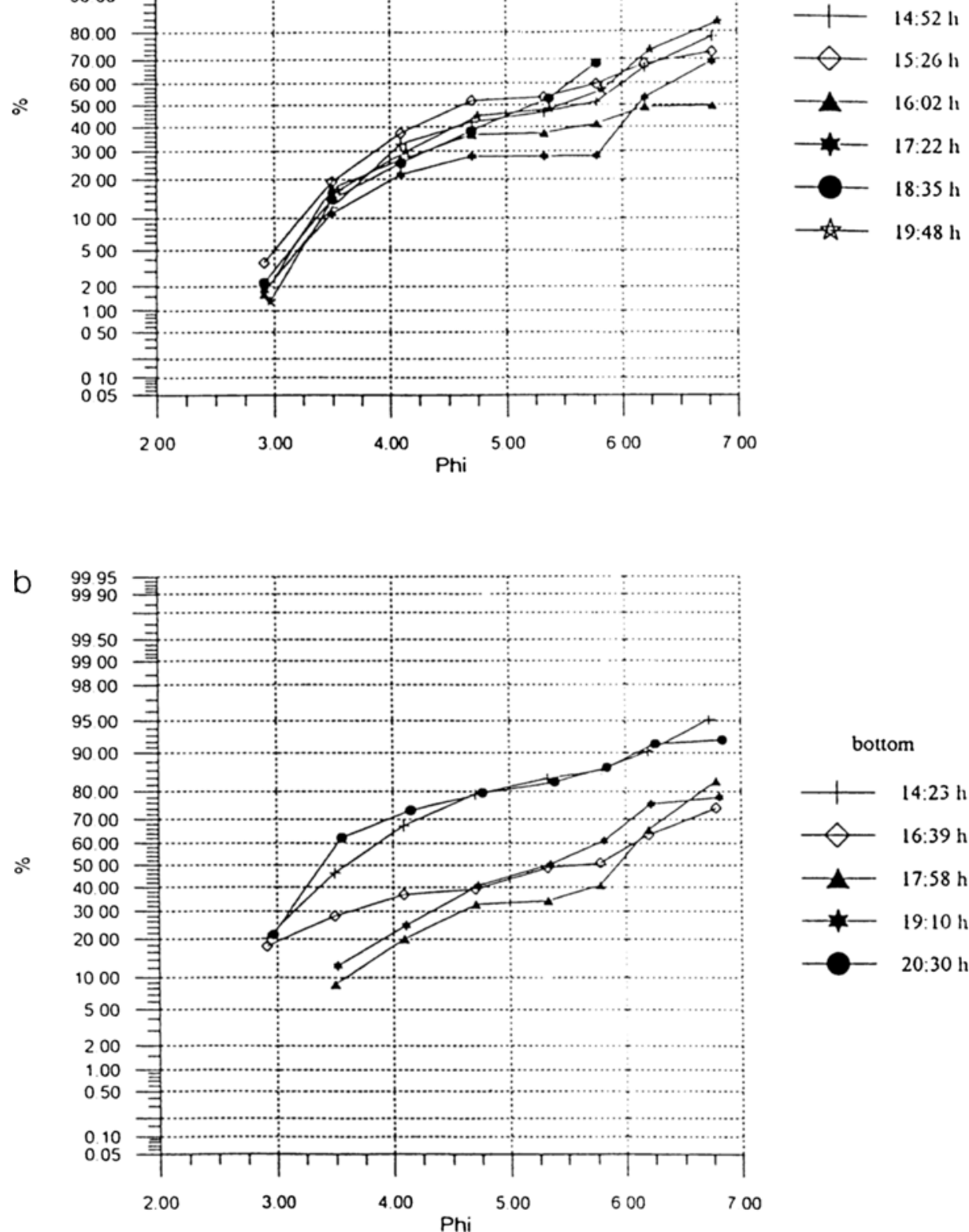

bottom

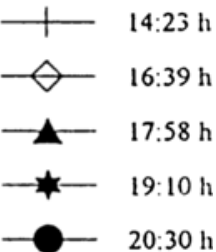

Fig. 7. Diagrams illustrating cumulative grain sizes; a: surface, b: bottom 
at the beginning of the flood period and at the end of the ebb period, when the squared current velocities are at a maximum.

The settling tube analyses show the highest concentrations at the bottom. Here, median settling diameters follow the temporal variation of concentration related to current velocities, thus the highest values are to be found at the beginning of the flood period and at the end of the ebb period. At the surface, the median particle diameters are almost constant, being linked to the small variation in overall concentration levels.

Acknowledgements. This study was made possible by financial support from SWAP (BMBF). This is publication no. 270 of the project "Ecosystem Research Wadden Sea". I would like to thank my colleague, Michael Larsen, for assisting with the field work.

\section{LITERATURE CITED}

Bale, A. J., Barrett, C. D., West, J. R. \& Oduyemi, K. O. K., 1989. Use of in-situ laser diffraction particles sizing for particle transport studies in estuaries. In: Developments in estuarine and coastal study techniques. Ed. by J. McManus \& M. Elliot. Olsen \& Olsen, Fredensborg, 133-138.

Burt, T. N., 1986. Field settling velocities of estuary muds. In: Estuarine cohesive sediment dynamics. Ed. by A. J. Mehta. Springer, Berlin, 126-150.

Dyer, K. R., 1986. Coastal and estuarine sediment dynamics. Wiley, Chichester, $342 \mathrm{pp}$.

Edelvang, K., 1995. The significance of flocculation in the estuarine environment. PhD-thesis, Univ. of Copenhagen, Copenhagen, $111 \mathrm{pp}$.

Edelvang, K. \& Austen, I., 1997. The temporal variation of flocs and fecal pellets in a tidal channel. - Estuar. Coast. Shelf Sci. 44, 361-367.

Edelvang, K. \& Larsen, M., 1995. The flocculation of fine-grained sediment in the estuary of Ho Bugt, Denmark. - Folia geogr. dan. 22, 1-120.

Eisma, D., Chen, S. \& Li, A., 1994. Tidal variation in suspended matter floc size in the Elbe river and Dollard estuaries. - Neth. aquat. Ecol. 28, 267-274.

Fennessy, M. J., Dyer, K. R. \& Huntley, D. A., 1994. INSSEV: An instrument to measure the size and settling velocity of flocs in situ. - Mar. Geol. 117, 107-117.

Kranck, K., 1975. Sediment deposition from flocculated suspensions. - Sedimentology 22, 111-123.

Krone, R. B., 1978. Aggregation of suspended particles in estuaries. In: Estuarine transport processes. Ed. by B. Kjerfve. Univ. South Carolina Press, Columbia, 177-190.

Lackschewitz, D., 1995. Besiedlungsmuster des Makrobenthos im Sylt-Römö-Wattenmeer. SWAP Teilprojekt 2.2/2.3/3.2. Bundesministerium für Forschung und Technologie, Bonn, $52 \mathrm{pp}$.

McCave, I. N., 1984. Size spectra and aggregation of suspended particles in the deep ocean. - Deep Sea Res. 31, 329-352.

Pejrup, M., 1988a. Flocculated suspended sediment in a micro-tidal environment. - Sediment. Geol. $57,249-256$.

Pejrup, M., 1988b. Suspended sediment transport across a tidal flat. - Mar. Geol. 82, 187-198.

Sternberg, R. W., 1971. Measurements of incipient motion of sediment particles in the marine environment. - Mar. Geol. 10, 113-119. 